\title{
Access and Use of Information by Rural Communities in Arid and Semi-arid Lands (ASALs) of Kenya: the Case of Maarifa Centres
}

\author{
Catherine W. CHEGE ${ }^{1 *} \quad$ Joseph, KIPLANG'AT ${ }^{2} \quad$ Daniel Chebutuk, ROTICH ${ }^{3}$ \\ 1.Department of Library, Records Management and Information Studies, School of Information Sciences Moi \\ University \\ 2.Department of Library, Records Management and Information Studies, School of Information Sciences Moi \\ University \\ 3.Department of Publishing and Media Studies, School of Information Sciences, Moi University, Department of \\ Information Science, University of South Africa
}

\begin{abstract}
Telecentres are community knowledge centres that offer shared access to information and Information Communication Technologies (ICTs) for the benefit of community development in alleviation of poverty. This article presents a case study that explored the extent to which rural communities in ASALs region of Kenya access and use information from the Maarifa centres (MC). The objective was to examine access and use pattern of information by ASAL communities benefiting from the MC. Using a multiple case study, 80 respondents drawn from five Maarifa centres were interviewed. The respondents were users of the respective Maarifa centres. The Maarifa centres selected were namely; Nguruman MC in Magadi, Mutomo MC in Kitui, Isinya MC in Kajiado, Ng'arua MC in Laikipia and Sipili MC in Baringo. Further, five focus group discussions were conducted with the respondents. Key informants interviewed included, Director of Arid Lands Information Network (ALIN); Programme Coordinators of Maarifa centres; Officers of the Communication Authority of Kenya and the ICT board of Kenya. Major findings indicate that rural communities appreciate Maarifa centres as a source of information. The respondents valued Maarifa centres as intermediaries for accessing information for socio-economic development. The biggest achievement is the use of Sokopepe, an online knowledge management platform which can be accessed through computers or the mobile phone. The challenges that hinder effective access and use of information are mainly infrastructural which slow down information uptake and internet access. The study revealed that Maarifa centres have addressed most of the community's information needs of government information through access to e-government services; e-commerce, agricultural development and knowledge creation, resulting in improved livelihoods. Provision of these services was possible through collaboration of the government ministries and agencies, development partners, funding agencies and community participation.
\end{abstract}

Keywords: Telecentres, Information access, Knowledge management, ASALs

DOI: $10.7176 / \mathrm{IKM} / 10-5-04$

Publication date:August $31^{\text {st }} 2020$

\section{Background Information}

Telecentres are information centres established to provide information resources and services particularly to people living in marginalised areas. These telecentres facilitate access to information by use of computers and other ICT gadgets. While provision of information is the major function of telecentres, it is also a key player in any development. Relevant and accurate information plays critical role of enlightening farmers and pastoralist on what, how, and when to farm, and how best to rare cattle. In addition, farmers are educated on how to market and where to find market for their produce thus operating a knowledge economy. The World Bank (2009) report explains that "...use of knowledge creates greater socio-economic development..." which is made possible through access to factual information and knowledge.

Arid Lands Information Network (ALIN) is a non-profit, non-political non-governmental organizations (NGO) is a chain of grassroots Community Development units of workers drawn from other NGOs, communitybased organizations (CBOs) and government departments. ALIN's focus of work is on the ASALs within the African Great Lakes regions. The units that form the network perform extension services in different fields of competencies. ALIN acts as a source of information and knowledge for communities they serve. ALIN is knowledge-driven society whose aim is to enhance livelihoods of communities by means of information exchange. It has been in operation for fourteen years in the Eastern Africa region. Their services are focused on providing rural communities in Arid and Semi Arid Lands (ASALs) with information and knowledge using ICTs. Their main activity is to train them the skills that can enable the access to information and knowledge through telecentres referred to as Maarifa centres.

ALIN facilitates information transfer to and between extension workers or informediaries and ASAL communities in Kenya, Uganda, Tanzania and Ethiopia. The information transfer mobilisation targets smallscale sustainable agriculture, climate change adaptation, natural resources management and other livelihood 
issues. Maarifa centres are an initiative of ALIN which came to be because of an increased demand for telecentre services and the need to document local knowledge (ALIN, 2012)

\subsection{Maarifa centres}

Maarifa is a Kiswahili word meaning "knowledge". Maarifa centres are public access which are established and managed by ALIN. They play a role in offering relevant information and acts as centres for local knowledge documentation. They are equipped with ICT tools to help enhance information generation, and access. The centres were established with an aim of enlarging information and knowledge scope of communities and empower them to turn past experiences into lessons. These centres act as referral points for communities in terms of information access. (Nguo, 2015)

Some of the Maarifa centres were first established in 2006 (Ng'arua and Sipili), while others in 2007 (Mutomo, Isinya and Nguruman) and are distributed in the ASAL regions of Kenya. These telecentres started as "access points" for disseminating information and were run by focal groups comprising of community development workers from public and private sectors. A field officer runs each centre with the help of an advisory committee from the community.

\section{Literature Review}

An interrogation of the literature gives an insight of the trends in access and use of information through Telecentres. Telecentres helps to overcome poverty, digital divide, enhances accessibility to information which contribute to local and national development. Poverty is a common characteristic in rural areas. Many studies for example, Heeks, (2003); United Nations Development Programme [UNDP], (2011) and Sein et al, (2008) note that "... the poor are poor because they are not only needy of basic resources and socio-economic prerogative to life; they also experience insufficient access to information." Telecentres are supposed to provide affordable access to ICT especially basic computer skills and familiarity with the World Wide Web. Kapondera (2014) while opening a telecentre in Malawi commented

"Much of the deficiency in our midst, much of lack of knowledge among the population, much of the seclusion in our communities, can be addressed when people access information that could help them tackle issues affecting their lives."

Gomez et al (2013) explain that socially, "telecentres provide a positive environment that distracts youth from participating in social evils such as drug abuse and crime which have penetrated and are rife even in rural poor communities.

The primary objective of telecentres is to address the marginalised and rural communities' demand for information and communication. Proenza et al (2001) and other information scholars such as Islam and Hoq (2010) emphasise that telecentres enhance accessibility of information among marginalised communities. Telecentres provide access to information to the public since they are shared facilities. ALIN has established Maarifa centres to help rural people in ASALs access information. Maarifa centres are equipped with computer facilities, and are involved in training people in computer skills. The main role of Maarifa centres mandate are to "avail easy access to information and knowledge resources; improve community livelihoods through access to new knowledge and innovations; engagement of youth in productive activities and access to IT skills" (ALIN, 2012).

Rural development can make a considerable contribution in national progress therefore provision of accessible information is necessary to the developmental activities of the rural communities. Easy access and flow of information is facilitated by ICTs. Many rural populations cannot individually access information technology due to marginalisation, isolation and the fact that they cannot afford to buy such facilities. Access to information in the rural areas using ICTs is made possible through the telecentres. Telecentres empower rural marginalised communities to use modernised information innovations for their development (Mahmood, 2005).

Telecentres are conceptualised as 'public community centres that provide shared access to information and technologies for reasons of community advancement and poverty reduction' (Murkerji, 2013). They offer solutions to digital divide and include the "underserved" communities in the socio-economic benefits. "Underserved" are communities that experience inadequate access to basic necessities such as electricity, health, social welfare among others. (Osman and Tanner, 2017; Bailey and Ngwenyama, 2009). Telecentres are located in communities where ICTs, internet and related equipment are not affordable to individuals and the services are provided at a subsidised fee or completely free of charge. The common denominator in the definition of a telecentre is the commitment to advance communities' well-being in terms of agricultural development, better education, health-care and enterprise opportunities and overall improvement of life (Bailey and Ngwenyama, 2010). Telecentres go by different names such as multipurpose community centres, community knowledge centres, village information centres, internet access point and others. They also operate under different models such as they are sometimes embedded into existing institutions such as community organizations and libraries. 
Telecentre movement began in the 1980s with support from the development agencies such as International Telecommunication Union (ITU), United States Agency for International Development (USAID), United Nations Development Programme (UNDP), International Development Research Centre (IDRC) and United Nations Educational, Scientific and Cultural Organization (UNESCO). These agencies created telecentre.org (an e-portal that supports networks of telecentres around the world (Colle, 2001). Telecentres have with time transitioned from just being public access point to computers and the internet, printing services and offering basic ICT training to offering a range of specialized services. People in the rural environment overcome computer illiteracy barriers through training offered at telecentres (Kapodera, 2014). They offer specialized ICT training to upgrade skills for example in small businesses, and programming languages used on applications such as java, egovernment services, telemedicine facilities, e-learning, teleworking and socio-digital innovation (Manuel, 2012). Gcora et al, (2016) confirm this by saying that telecentres apply technologies to improve people's lives by use of information technology (IT) innovation to make communities stronger and more connected. The common element to pick from the definition of a telecentre is access to information through digital technologies and access to communication because information only makes sense when it is communicated. Right and relevant information will influence informed decision-making for a better future.

Telecentres offer employments opportunities since they provide information, knowledge as well as computer literacy skills. Osman and Tanner (2017) confirm that computer training programmes in telecentres enable people living in rural remote areas improve their employability. They can eventually take up the many opportunities provided at the telecentres and elsewhere. They also save rural communities travelling costs and time to access services which would otherwise only be available in urban centres (Kapondera, 2014).

\section{Problem Statement}

Most rural parts of Kenya are agro-based. While information provision is considered central to the success of rural development initiatives, these rural communities are characterised as information-deprived. People in rural areas especially the poor lack access to essential information that can improve their livelihoods. Kellerman, (2014) rightfully said that "many people within these communities have limited basic computer literacy skill resulting in employment barriers and in some cases criminal activities". These rural communities can only be empowered if relevant information is made available and accessible in the format and language that they understand.

There is the general belief that ICTs enhance access to information, and an adequate access to information results in social and economic improvement in a society. Islam and Hoq (2010) correctly emphasise that information that is not used has no inherent value. Consequently, use and impact of information depends on access to it. Mtega and Melakani (2009) argue that poverty in African countries is caused by among other factors, poor information infrastructure and access.

The aim of this paper is therefore to assess how Maarifa centres facilitate access and use of information to rural communities living in ASAL. The paper examines the challenges that impede access to information and suggest possible solutions to address the challenges.

\subsection{Research questions}

The paper sought to answer the following research questions:

- What information sources and services are found in Maarifa centres and in what format?

- How do users of the selected Maarifa centres access and use information resources and how has information access helped the local communities in improving their livelihoods?

- What challenges are experienced by Maarifa centres in the provision of information to rural communities in Kenya?

- What measures can be taken to improve the provision of information services to rural communities in ASALs?

\section{Research Methodology}

Both primary and secondary sources of information gathering methods were applied. Secondary sources involved review of available empirical literature related to the study, analysis of methodologies and findings from primary sources of information were also reviewed.

The study employed mainly qualitative approach and selected 80 users from the five Maarifa centres. In addition, key informants were purposively identified. Informants comprised the managers of the centres, Director of ALIN; and officers of ICT Board of Kenya and Communication Authority of Kenya (CA). Five Focus Group Discussions (FGD), with users who were randomly selected at the Maarifa centres were conducted. Five participants to Focus Group Discussion were selected from each centre. Further, an observation method was employed to gather information on the operations of each Centre. A prescribed observation guide was used where relevant parameters were provided for observation. The three methods provided triangulation of the 
findings.

Various categories of relevant entities including; key informants, managers and users of Maarifa centres were interviewed using prescribed semi structured interview schedules. Demographic questions were closeended and constituted the quantitative method. Data collected using quantitative methods were analysed using descriptive statistics. The open ended questions were coded and transcribed. Data from qualitative approach were analysed using thematic technique. Open-ended interview questions encouraged the researcher to obtain more information. The prepared interview questions ensured uniformity of questions asked to all categories of respondents, hence ensuring reliability of data. (Mixed method approach helped to minimize problems experienced with the use of a single method approach. Diverse types of data collection provided an understanding of the research problem (Creswell, 2003).

\section{Findings of the Study}

The study findings are guided by four research questions centred on information sources, formats and services; users and access to information at Maarifa centres; challenges experienced during the process of accessing information and recommendations on how to improve information services in ASALs of Kenya.

\subsection{Users and access to information}

The information services offered by Maarifa centres are to a large extent explain how information is accessed and used by the potential users. From the FGDs, the study established that people understood telecentres and Maarifa centres to be places to access electronic information via the Internet, print books and DVDs, and a place to be trained in computer skills. The main aim of Maarifa centres is to improve ICT skills, increase local content and open rural areas to opportunities to ICT related services such as marketing and accessing competitive prices of produce and outsourcing among other services (Nguo, 2016). Other studies on telecentres reveal similar findings because access to ICTs is considered an important driver and an important input for economic development (Walsham 2010, Furuholt and Saebo 2017). For instance, service offered at Malawi's Vikwa telecentre revealed that farmers access information that help them increase their incomes, check prices online and easily communicate with buyers of their farm produce (Kapondera and Namusanya, 2017).

Respondents also stated that information is accessed at community-based Maarifa centres through a range of channels such as; "Web portals", "Web 2.0 applications", "mobile phone platforms" such as Sokopepe application that has been innovated by ALIN to enhance access to information by ASAL communities, and through "workshops" in collaboration with the Ministry of Agriculture, "exchange visits" and "regular print publications" for instance Baobab Journal.

Telecentre managers explained that users visited Maarifa centres for personal communication, business communication, buy goods or services, sell goods or services, search for information and get assistance on administrative matters. Maarifa centres are therefore adduced as very important institutions where the rural communities in ASALs in Kenya visit to access information and other services using modern technologies to improve their livelihoods.

A similar study conducted in Mozambique by Rega, et al (2013) revealed that people visited the telecentres to train and obtain ICT skills and to access internet. Kapondera (2014) found out that Malawi people visited Lupaso telecentre for learning purposes. Besides learning, Mbatha (2015) explained that people visited telecentres for social purposes such as communicating with friends . Buhigiro (2012) said that some users visited telecentres to look for jobs online, to access agricultural information on various products and to learn the best practice farming methods.

Maarifa centres' managers' categorised users as mainly from the local community, students - both high school leavers and those in institutions of higher learning, farmers, civil servants and teachers, business community and the self-employed. This means that Maarifa centres serve as a critical source of information to a diverse category of users in ASALs rural communities of Kenya. The youth constitutes the majority in telecentre users. Parkinson (2005) noted that majority of users of telecentres around world are the youth because of their affinity to ICTs. An IDRC study on Uganda, Latin America and Mozambique confirmed that the male youth are the majority users of telecentres (Etta and Parvn-Wamahiu, 2003 and McConnel, 2006). Other categories of users visit telecentres strictly to satisfy their information needs.

A question was asked how Maarifa centres' users accessed the same services before the telecentres were established. Respondent from Isinya explained that he visited cyber cafes in the urban areas closest to where he lived. One respondent from Mutomo said she mobile phones to surf the internet. But a user in Ng'arua and another one in Mutomo were quick to mention that they had to travel to far off distances to access the same services he now get at the telecentre like the library services and computer services.

This shows that Maarifa centres are essential facilities because compared to other available information services providers, they have enhanced access to information. All the users agreed that services are offered free of charge, hence cheap and easily accessible. From these findings, it is clear that Maarifa centres improve 
people's lives, for instance, training is important as it helps develop competencies that telecentre users need to improve their human capital. Relevant training will then enhance users' financial assets because trainees will be able to apply skills acquired (UNCTAD 2007).

Additionally, Maarifa centres are crucial facilities because they are able to meet rural communities' diverse information needs. The users are able to access a wide range of information services and resources in the telecentres. The main purposes of using the telecentre can be compounded as: receiving ICT training, searching for information to satisfy their livelihood needs such as agricultural, health, educational since some respondents were distance learners e.g. one from Isinya and personal communication with friends and relatives who live far. This means that Maarifa centres contribute to improved quality of life in the areas of information and knowledge.

\subsection{Type of information sought by users}

The paper aimed to find out strategies put in place to ensure that users of Maarifa centres get access to relevant information that satisfy their needs. From the findings, the Maarifa centres' managers explained that every centre has an enquiry desk where farmers and other centre users presented their problems and needs to staff stationed there. Hence, Maarifa centre staff are charged with the responsibility of coming up with solutions and answers to problems and questions presented to them by the clients. Additionally, Maarifa centres are also instrumental in identifying the needs of the local communities through regular researches that are conducted in relation to the information needs of the locals. This in turn identified home-grown solutions that are most applicable and relevant to the local situations. Therefore, Maarifa centres are helpful in improving the livelihoods of rural communities.

The study also sought to find out statistics of Maarifa centres usage as per the data collected and analysed at Maarifa centres. The findings indicated Maarifa centres carry out needs assessment which in turn helped in identifying community information gaps that required to be bridged to facilitate socio-economic development. This is attained through the inquiry desk. The statistics also indicate that more men the gender of users, majority of the users in all Maarifa centres sampled were male; with $60 \%$ (30) representation in Mutomo, 55\% (27) in Isinya, 60\% (30) in Ng'arua, 80\% (40) in Nguruman and 70\% (35) in Marigat use the telecentres as compared to women. There is high use of information by the community leading to different innovations that facilitate economic empowerment.

\subsection{Computer training}

Seretse et al (2014) stated that ICT literacy is a tool that facilitates access to information. Computer training constitutes a core mandate for Maarifa centres. The study inquired from the telecentres' users their reason for attending computer training at Maarifa centres. $80 \%$ (40) of the respondents indicated that they attended computer training to acquire modern information technology and to gain computer skills. Internet and other information technology services such as information access are provided by Maarifa centres to rural communities in ASALs. This illustrates that users relied on the computer training offered at Maarifa centres to update themselves on modern information technologies and to build their capacity in use of ICTs. This point to the critical role that Maarifa centres play in building ICT capacity of the rural communities in ASALs and bridging the digital divide. This is because Maarifa centres are the only places where majority of users in ASAL can learn computer and other IT related skills.

Respondents were further asked to indicate in what ways the training had been useful. The findings from FGD showed that majority of the telecentres' users are equipped with the skills of exploiting electronic information services offered in Maarifa centres such as using computers to:

- $\quad$ access online information e.g. health and agriculture

- $\quad$ access internet especially the jobs listing portals to look for job vacancies

- access e-government services e.g. filing iTax returns, renewal of driving incenses among others

- $\quad$ send e-mail or to chat with people outside the community

- $\quad$ get updated in news through reading newspapers and magazines

- do college/school assignments

- create a community newspaper or magazine

- $\quad$ apply for scholarship

$\bullet$ visit social networks like face book read market blogs or conduct Google searches

In reference to UNCTAD (2007), "the greatest impact of a telecentre comes from the acquisition of new skills which in turn enhance their economic activities". The findings illustrate that majority of the telecentres' users are equipped with the skills of exploiting electronic information services offered in Maarifa centres. It further 
indicates that Maarifa centres have sufficiently empowered the rural communities in ASALs in accessing information through the internet which has consequently opened new opportunities of learning new ideas that they could apply to better their lives.

\subsection{Sokopepe services}

Nguo (2013) explains that Sokopepe.com is an ALIN innovation that facilitates access to information to people living in ASAL. Sokopepe application is a virtual service accessible online and on mobile phone. Activities through Sokopepe can be concluded on a mobile phone handset by means of short messaging service (SMS) facilitating wide access to farmers in remote areas once they have registered. The aim of ALIN is to harness the power of ICTs in enabling farmers to competently access and exploit a fair market for their produce.

Sokopepe was introduced to bridge the information gap by providing farmers and livestock keepers with a "one-stop information platform" that is always available and easy to use. Sokopepe services include information on: commodity prices, farm inputs, linkage with other service providers, and livestock tips as well as secure mobile payment systems. Sokopepe is particularly good for women and youth who were previously excluded from the mainstream empowering them to participate in the agriculture value chain at various levels. Farmers and pastoralists anticipate a transformation in farming and access to markets as an opportunity to improve their livelihoods.

The mobile phones to a large extent have solved the problem of access to information in ASALs. Based on observation at Maarifa centres and their environs, it was found that majority of the people have mobile phones. The mobile phone service coverage in Isinya, Marigat, Ng'arua, Mutomo and Nguruman is adequate especially through the Safaricom mobile services network. This shows that the ICT infrastructure in the rural areas in Kenya is sufficient and can be exploited to increase access to information to the rural communities. ALIN has embraced the use of mobile phone to disseminate information among the ASAL communities.

\subsection{Perceived benefits witnessed in peoples' lives since establishment of Maarifa centres}

From the FGDs, the study established that there are a number of changes witnessed in people's lives the establishment of Maarifa Centres. Some of the benefits include:

- Creating new possibilities for the locals to improve their livelihoods such as learning better farming methods as well as marketing their agricultural produce through Sokopepe.com. Maarifa centres have also reduced the cost of accessing information since services are offered free of charge. This translates to improved social, human and capital assets.

- Learning computer skills and how to use the internet, gaining access to more information, learning new farming skills and, residents have developed interest in learning IT skills up to advanced levels. They also benefit from access to real time news, increased participation in social life, improved social lives; they are more enlightened, and have more access to marketing information and modern methods of farming.

- Farmers easily access information on farm inputs, prices, the existing prices of farm and livestock products. They access to information on improved livestock keeping practices, disease prevention and various methods of farming is now fast.

\subsection{Relationship between Maarifa centres' services and socio-economic development}

The study sought to establish the relationship between the services offered by Maarifa centres and socioeconomic development of the beneficiary communities. The managers stated that there is a positive relationship because the services offered are in line with the communities' socio-economic needs that enhance livelihoods Since Maarifa centres have helped users in:

- Supporting existing economic activities

- Developing new economic opportunities

- Improving self-employment opportunities

- Improving salaried employment opportunities when they get promoted or transferring to better employment after acquiring new skills.

The study further found out the changes observed in the lives of Maarifa centres' users as a result of using information provided at Maarifa centres. The managers indicated that users have increased their confidence levels in computer use; quality of life has improved as a result of making informed choices, access to quality services and, more social interaction between the people through the social networks, better integration of farmers with service providers, improved income levels, and access to information on market trends. Additionally, the users have better access to public goods and services and improved health as they know better ways of disease prevention and control. Telecentres managers further indicated that ICTs contribute to socio- 
economic development of the people living in ASAL communities, such as promoting new knowledge which prompts replication and enhances change of practices.

\section{Challenges in Providing Access to Information}

The second research question was to analyse the challenges experienced by the Maarifa centres in the provision of information to rural communities in ASALs in Kenya. Zahurin, et al. (2009) explains that setting up telecentres in remote rural locations comes with many challenges such as lack of infrastructure, human resources and logistics. This research found that accessibility is constrained due to the rugged nature of the terrain, limited income, unreliable power supply especially from the national grid, forcing them to depend on alternative electricity supply such as solar and generators. Other shortcomings include lack of trained personnel, lack of awareness and resistance to change; and, community's failure to readily accept new technology. These are the challenges that normally face telecentres as they promote economic opportunities and enable telecentres to support livelihoods in remote areas. ALIN specifies the main barriers of information access and use are illiteracy, language and lack of ICT skills. The findings of this paper further established the following challenges:

\subsection{Literacy and language barrier}

Literacy is looked at as both formal and functional, whereby it is a core factor facilitating widespread access to ICTs by all stakeholders in the community, be they farmers, small scale entrepreneurs and traders among others. This study relied on the available literature to establish literacy characteristic in communities where Maarifa centres are located. It was found that literacy levels among the rural communities in the five selected centres are low. This means the majority of the rural communities in ASALs have poor academic backgrounds. This slows down the rate at which the rural communities benefit from the Maarifa centres because their poor academic background limits their understanding of the ICT training. It also slows down the rate of diffusion of technology and information.

Illiteracy also presents a language barrier. The findings are similar to those of Mansell and When (1998), who maintain that "illiteracy is the fundamental barrier to participating in knowledge societies". Illiteracy presents a problem because most of those targeted in rural areas are illiterate; they not only lack formal education but also have low levels of computer literacy. This adds on to another problem of slow uptake of technologies by users served by Maarifa centres. Language barrier hinders access to information especially if information is packaged in scientific language. Besides, information in the internet is mainly in English which is not a common language for the rural communities (Mansell and When, 1998).

\subsection{Location of the telecentres}

The distance factor has been described as very important by Benjamin (2002), who defined it as "catchment area". Telecentre catchment area ensures that people access information services within walking distance from their residential areas. Many respondents were happy about the location of Maarifa centres because of the shrunken distance. It made it convenient for them to access Maarifa centres. Pick (2013) confirms that "the location of a telecentre influences its use through relationships to local user markets, transport access, convenience, availability of local ICT workforce, and cultural aspects of communities".

One of the challenges experienced in access to information in the rural areas is that telecentres are a few and scattered. What has been deduced from the literature is that, ALIN has eight telecentres serving the large proportion of the population that lives in rural areas.

\subsection{Types of telecentres}

Gomez et al (1999) describe the various types of telecentres as basic telecentre, civic telecentre, cyber café and multipurpose community telecentres. Maarifa centres fit in the category of basic telecentres that provide limited information services. Gomez (1999) further describes a basic telecentre as the one located in a rural or marginalised area, where the population has limited access to information services and hardly uses sophisticated technologies. This research deduced that ALIN deliberately started with the basic telecentres' model for people first and foremost to learn and diffuse technology, because communities who were initially served by Maarifa centres were early adapters and their literacy levels and information literacy were quite low. Mtega and Melakini (2009) point out that it is necessary to know all community variables related to information needs before deciding to provide a certain information service through a telecentre, a direction seems to have been taken by ALIN through Maarifa centres in ASALs. ALIN directors later felt that there could be a mismatch between technology trends and the idea of having fixed means/location of accessing knowledge. They explained that the future is in mobile phones, hence the move to consolidate Sokopepe to use the online space that will be accessed through mobile devices, particularly the mobile phone. Sokopepe is aimed at harnessing the power of information and communication technologies in enabling farmers to efficiently reach out and exploit competitive markets for their produce (ALIN 2013). 


\subsection{Infrastructure}

The study established that rural areas have poor infrastructure which hinders the functionality of the Maarifa centres' full operationalisation. The findings concur with Munyua (2000) and Prado (2009) who indicated that rural areas commonly lack communication lines; have low bandwidth, inadequate or insufficient equipment and also suffer from scarce/lack of connectivity and, unstable power supply which is an obviously primary constraint. However, power generators can be used if electricity is not available. Poor roads limit access to the telecentres by communities who are geographically isolated. They suffer from inadequate access to physical markets and inadequate market information. Munyua (2000) stipulates that new ICTs are not such affordable means of expanding rural information systems. Besides, Prado (2009) noted another infrastructural factor that limits the optimal adoption of ICT initiatives being telecommunication infrastructures which do not reliably support connectivity. There are also scarce skilled personnel on the ground capable of operating and maintaining ICTs.

Based on the findings, Maarifa centres have limited space, the description given in ALIN website is a fabricated shipping container, which can only accommodate few computers in addition to slow internet connectivity as explained by the centres managers.

\subsection{Too basic training programs}

Although computer training constitutes the main activity at Maarifa centre, the trainings are mostly on basic computer skills, at the same time users' lack of information skills among the users which makes effective use of sophisticated ICTs impractical in rural communities. The finding corroborates earlier findings by Githinji (2011) who also found that lack of information skills makes effective use of sophisticated ICTs impractical in rural communities.

\subsection{Cultural barriers}

The study established that there was gender disparity in the utilisation of the Maarifa centres in provision of information as more men than women visited the facilities. This is likely contributed by the cultural barriers and perceptions in the rural communities that hinder women in accessing the information services in the Maarifa centres. According to Githinji (2011), the Maasai women in Kenya for instance are not allowed to mingle with men; they are therefore constrained in exploiting resources at Maarifa centres. Perceptions are also barriers as many view new technologies as a preserve of another class preferable the educated, the young and the rich (Githinji, 2011).

\subsection{Communities' attitude}

The study sought to find out the major constraints that needed to be removed so that telecentres performed or operated better. Maarifa centres' managers indicated that there is negative attitude towards use of computers because the older generation members of community think that computers are meant for highly learned persons. Language barrier also limits community access to information. Most of the information is written in English and the level of community literacy is low. Poor infrastructure also hinders the functionality of the Maarifa centres as necessary infrastructure is required for the full operationalisation of the Maarifa centres.

\subsection{Sustainability}

The study sought to find out problems that Maarifa centres face in acquiring and maintaining ICTs. Maarifa centres' managers indicated that there were inadequate funds to purchase ICT devices, rampant virus attacks, frequent power failure, and internet connectivity challenges. Declining donor interest in funding the telecentres is also posing a threat to the sustainability of Maarifa centres.

\subsection{Community's related problems}

The study sought to find out the biggest community-related problems facing area residents before the telecentre project came in. The managers indicated that there were very low literacy levels, low awareness levels on agricultural information and low information in ICT training, leading to the present digital divide in Kenya. This is attributed to the limited or no access to information services due to lack of ICT platform, low reading culture that affects information uptake in rural communities in ASALs.

To avoid community related problems, ALIN's used an approach that involved communities in the management of Maarifa centres and worked with hosting organizations for instance, Mutomo MC is hosted by the Mutomo Mission Hospital; Isinya MC is hosted by the Maasai Rural Training Centre (MTRTC). This approach has been highly successful, winning several national and global awards, such as the Bill and Melinda Gates Foundation's Access to Learning Award (ATLA) in 2011; and UNESCO's International Price for Rural Communication given under its International Programme for Development of Communication (IPDC) 2012. 


\section{Strategies for Overcoming Maarifa centres' Operational Challenges that Impend Access}

The directors were asked to indicate the strategies that ALIN deploys to counter the challenges facing the implementation of Maarifa centres across ASALs. According to the findings, the strategies include; community involvement in running Maarifa centres, working with hosting organisations in some areas, locating field officers to run the day-to-day operations at Maarifa centres, and building networks and partnerships with government, private sector, civil society and local communities thus embracing the concept of public private partnership (PPP). These strategies made the community appreciate the partnership with Maarifa project and are encouraged to exploit the opportunities extended by ALIN.

From the FGDs, it was recommended that there should be expansion and scaling up of the Maarifa centres to improve their performance and access as they serve more rural communities in ASALs. Other recommendations include: increasing the number of computers and trainers, adoption of alternative power sources to cope with power shortages, improvement of the internet speed, provision of more updated ICT reference books, improved provision of security, provision of more programmes and software, introduction of other information services like printing, photocopying services and e-learning.

\subsection{Technology}

The technological component which involves selection of appropriate hardware and software, network access and equipment helps in improving the technological environment. The problem of obsoleteness of computer software, paying electricity bills and logistics for transporting the computer systems interferes with the provision of and access service to clients. The aim of this research was to find out how this problem is addressed by the telecentres under study.

The speed of ICT development almost left ALIN behind. When ALIN directors were asked to explain the progress achieved in the implementation of Maarifa centres, they explained that having reached its peak in 2012, there was a concern of becoming outdated due to mismatch between technological trends and the idea of fixed means/location of accessing knowledge. They explained that the future trend was in mobile phones, and hence ALIN's moved to embrace Sokopepe for online space where information would be accessed through mobile devices, particularly the mobile phone. Sokopepe is aimed at empowering the farmers to effectively use information and communication technologies to competitively market their produce (ALIN 2013). The Director ALIN asserts that mobile phone has become a "Maarifa in the hand".

\subsection{Strategies Employed by Maarifa Centres to Overcome Access Challenges}

The study sought to find out strategies that the Maarifa centres' managers used in trying to overcome or solve access-related problems. The managers indicated that there was a continuous resource mobilisation through fundraising and income generation activities such as charging a small fee to the users, taking computers with viruses to Nairobi city for repairs and installation of antivirus, limiting the use of unauthorised flash disks, using solar as an alternative source of power although it is not sufficient for all the computers and using modems for internet when the server fails.

Therefore, Maarifa centres have strategies to mitigate and cope with access challenges. They have alternative sources of power to keep the centre running in-case of power failures. The staff of Maarifa centres supervises users of the telecentres to ensure that they do not contribute to the breakdown of the systems. Maarifa centres managers also seek technical support from ALIN offices.

\subsection{Government Participation in Facilitating Access to Information at Maarifa Centres}

The Communication Authority of Kenya (CA) officers were asked to state the policies or strategies that CA has put in place to ensure wider accessibility of ICTs to the majority of Kenyans especially those living in ASALs; in other words, to ensure that Maarifa projects reach their beneficiaries.

Officials from CA explained that the Kenya Communications Act (2009) amendment provides for the establishment of a Universal Service Fund (USF), administered and managed by CA. The CA officers were asked to comment on the Kenyan ICT policy in fostering universal access to ICTs. According to the findings, the Kenyan ICT policy has been successful in achieving its objectives especially in fostering universal access to ICTs. This is shown by the increase in the number of internet users to $69.5 \%$ in 2015 up from $9.7 \%$ in 2015 as reported by Communication Authority of Kenya and International Telecommunication Union. This was a growth of $11.6 \%$. Similarly there is already in place an ICT curriculum from the Ministry of Education that is facing immediate uptake of the training.

CA officers further indicated that the corporation has supported the establishment of five Maarifa telecentres which were provided with various communication services. This enhanced ICT capacity in ASALs in Kenya through training and access to information. CA provided each Maarifa centre with a server, two computers, a printer, and free internet connectivity for one year. The centres are run and managed on behalf of the local people through partnership with ALIN which has sufficient experience in rural ICT development. 
The primary objective of establishing Maarifa centres is to build ICT capacity and skills development in the country. In addition, telecentres are the community access points mainly adopted for rural and disadvantaged areas to reduce the cost of individual ownership of equipment. Services like the Maarifa centres are offered free of charge to rural communities in ASALs in Kenya.

\section{Recommendations for Improving Information Provision}

The third task on this paper was to make recommendations for improving information provision to rural communities by Maarifa centres for sustainable livelihoods.

Telecentres' users agreed that the facility needs physical improvement in terms space, computers as well as the internet speed. This shows that Maarifa centres require continued technical, financial and material support to boast their effectiveness and sustainability. The areas that required assistance include capacity building and skills development of the implementing staff and the users, up scaling of the information services and financial support to make the services offered accessible to the rural communities in ASALs.

The FGDs' findings were in agreement that for the improvement of Maarifa centres' performance, they should be expanded and scaled-up in order to serve more rural communities in ASALs. Additional recommendations include improve infrastructure by increasing the number of computers and trainers; adoption of alternative power sources to cope with power shortages, expansion of the telecentres space; improvement of the internet speed; provision of more updated ICT reference books; improved provision of security; provision of more programmes and software; introduction of other information services like printing, photocopying services and e-learning.

\subsection{Measures to ensure telecentres' sustainability}

The study sought to find out measures taken to ensure telecentres' continuous use and hardware and software maintenance over a long period of time even without donor support. Maarifa telecentres' managers explained that the centres rely on open source software which does not require licenses. They have also partnered with other organisations to provide software at affordable rates. In terms of hardware, the users are trained on how to do basic computer maintenance.

\subsection{Best practices on telecentres as a source of livelihoods' support}

The study sought to find out best practice examples of how the telecentres support livelihoods. The managers explained that there is provision for exchange programmes among farmers to share agricultural information like installation of simple biogas. This has enabled the rural communities in ASALs to improve their livelihoods as they continue learning new technologies to enhance their agricultural productivity and other livelihood initiatives like energy generation.

\subsection{Progress achieved in the implementation of Maarifa centres}

The ALIN directors were to further indicate the areas in which Maarifa centres lagged behind. They explained that technology has advanced, while the centre trailed. Recognising the advance in technology, ALIN is now committed to move with the cutting edge technology by emphasizing Sokopepe over Maarifa centres.

In regard to lessons that telecentre initiatives could learn from ALIN, the directors indicated that telecentres should 'start with the people' and not the technology. The people- approach leads to understanding of technological solutions that solve people problems. Therefore telecentres' management should deploy the latest technology and empower the people to utilise and harness it.

\section{Conclusion on access and use pattern of information by rural communities}

Maarifa centres have been in existence for about eleven years, this study revealed that communities living in ASALs are accustomed to visiting the centres for various reasons. Most respondents said they visited the telecentres to access internet services, acquire computer skills, research, borrow books and other information materials, and for general socialisation. Maarifa centres are popular for providing access to a wide range of information services that enable them to improve their livelihoods. Evidence of reliance on Maarifa centres reveal that the establishment of the centres was relevant, convenient and optimum use of them is being made. That should be replicated across the country.

Additionally, the Maarifa centres are accessible to the local communities as evidenced from the findings, whereby $53.3 \%$ of the telecentres' users travelled for less than one kilometre to access the telecentres. This close vicinity coupled with the inquiry desk and capacity building from the free trainings, have not only empowered the users but effectively met their information needs, such as acquisition of computer skills, opening employment opportunities, and learning new ideas that could improve their livelihoods. This has also led to development of home-grown information solutions that are most relevant to the local situation, leading to selfreliance and self-sustainability. 
Maarifa centres have also reduced digital divide and communities are now able to freely use the internet for social networking, communicating via e-mail, and access to strategic online information, apply for jobs and scholarships, conduct online searches and study IT-related careers at advanced level. Furthermore, Maarifa centres have saved the communities' costs related to travelling, cyber cafe fee and purchasing textbooks, magazines and newspapers. ASALs communities are encouraged people to visit Maarifa centres and exploit the freely available information resources.

The centres have significantly improved users lives. Apart from gaining access to information on farming methods, markets and government services, it is evident there is career growth among the youth and the employed, in addition to receiving up-to-date information on farming from the local field officers who research using the internet.

Social media on the other hand has not only enhanced relationships but has also helped them stay in touch with the agricultural extension officers, thus sharing knowledge on better farming methods and income generating activities to boost their income. They also communicate with friends especially some of who are only accessible through the social network platforms. This shows that the internet has greatly enhanced the social life of the rural communities.

Most importantly, the new opportunities of accessing latest sources of information through the internet have kept them abreast with emerging developments around the globe making them global citizens. Users have access to diverse sources of information which increases opportunities to keep abreast and informed with global trends. Despite the accrued benefits from the study's findings, there are areas in which that the telecentres could improve to strongly promote livelihoods in the near future. These include marketing of agricultural produce and promotion of the formation of farmer organisations such as agri-business and cooperatives. Change strategy, for instance unlike before when people had to physically visit the centres, they now focus on the use of mobile devices to provide farmers with information and knowledge on agriculture and livestock value chains. This is done through Sokopepe, a globally recognized initiative of the Maarifa centres.

\section{Benefits of the study}

The study is important to ALIN, to the ICT board of Kenya and Communication Authority of Kenya. It will help in the formulation of information and communication policies. It is hoped that the findings in the study will educate Maarifa centres on how best to improve access to information and attract more users to the centres from ASALs in their quest of bridging the information/digital gap. The challenges identified should be dealt with to enable Maarifa centres effectively contribute towards the development of the communities they serve in ASALs. The study will also contribute to the growth of literature of telecentres as an instrument of development.

\section{References}

ALIN, (2012).” Maarifa Knowledge Centres". http://www.alin.net/12

Bailey, A. and Ngwenyama, O. (2009). "Social Ties, Literacy, Location and the Perception of Economic Opportunity: Factors influencing Telecentres Success in a Development Context". In Proceedings of the $4^{\text {th }}$ Annual Hawaii International Conference on System Sciences (1-11). Los Alamitos: IEEE computer Society.

Bailey, A. and Ngwenyama, O. (2010). "Community Mediation and Violence Prevention through Telecentre Usage: ICTs mediating the "Border Line". Proceedings of SIG globDev Third Annual workshop. Saint Louis, USA: Community Mediation and Violence Prevention through Telecentre Usage.

Benjamin, P. (2002). "Reviewing universal access in South Africa" . Southern African Journal of Information and Communication 1(2). http://link.wits.ac.za/journal/j0201-pb.html

Chharchhar, A.R and Hassan, S. (2013). "The Use of Mobile Phone among Farmers for Agriculture Development". International Journal of Scientific Research 2(6), 95-98. http://www.researchgate.net/publication/244484894_The_Use_Of_Mobile_Phone_Among_Farmers_for_A griculture_Development

Colle, R. D. (2001). "ICTs, Telecentres and Community Development". Information Technologies and International Development

Creswell, J.W. (2003). Research Design: Qualitative, Quantitative and Mixed Methods Approaches, 2nd edition. Thousand Oaks: Sage Publications Inc.

Duncombe, R. and Heeks, R. (1999). "Information, ICTs and Small Enterprises: Findings from Botswana". http://www.man.ac.uk/idpm/idpm_dp.htm\#devinf_wp

Fowler, F. J. (2009). Survey research methods. 4th ed. London: SAGE Publications.

Githinji, R.W. (2011). Application of Information and Communication Technologies for Development (ICT4D) in Rural Community in Kenya: An Ethnographic Approach, (Masters Dissertation). unitec.researchbank.ac.nz/handle/10652/1684

Gcora, N., et al (2015). "The challenges rural women face in using Telecentres: The case of the Eastern Cape Province). 9th IDIA conference. http://ir.muhas.ac.tz:8080/jspui/handle/123456789/2001. 
Gomez, R., Hunt, P., and Lamoureux, E. (1999). Enchanted by Telecentres: A Critical Look at Universal Access to Information Technologies for International Development. University of Maryland: College Park.

Gomez. R., Abokhodair, N., Bayo, L. and Park, M. ( 2013). "Computer Training to Day Labourers: a Heat Map to Address Emotional Barriers and Technical Skills". In Proceedings of the $46^{\text {th }}$ Annual Hawaii International Conference on System Sciences (2833-2841), Los Alamitos; IEEE Computer Society.

Heeks, R. (2000). Most E-Government-For-Development Projects Fail: How Can Risks Be Reduced? http://idpm.man.ac.uk/publications/wp/igov/index.shtml

Islam, A. and Hoq, K.M.G. (2010). "Community Internet Access in Rural Areas: A Study on Community Information Centres in Bangladesh". Malaysian Journal of Library and Information Sciences, vol. 15, No. 2 August, pp. 109-124. http://Ejum.fsktm.um.my/article 947.pdf

Kapondera, S. K. ( 2014). The Use of Multipurpose Community Telecentres and their services in Malawi: the Case of Lupaso Community Telecentre. http://hdl.handle.net/11394/4115

Kapondera, S.K. and Genevieve, (2016). "The Use of Multipurpose community telecentres and their services in Malawi: The case of Lupaso community telecentres". South African Journal of Libraries and Information Science, Vol 82, No. 1 (2016). http://sajlis.journals.ac.za/pub/article/view/1589

Kellerman, S. (2014). Computer Literacy Programs. http://www.dreamstoreality.co.za/computer=literacyprogram/

Kumar, R., and Best, M. (2006). "Social Impact and Diffusion of Telecentre Use: A Study from the Sustainable Access in Rural India Project". Journal of Community Informatics, 2(3). Retrieved from http://www.cijournal.net (Accessed 10/7/2010).

McConnell, S. ( 2001). Telecentres around the world: Issues to be considered and lessons learned. Retrieved from www.portal.unesco.org/telecentres+around+the+world.pdf

Mahmood, K. ( 2005). "Multipurpose community telecenters for rural development in Pakistan". The Electronic Library, 23(2), 204-220. http://www. reocities.com/khalidmahmood/mcts.pdf

Manuel, A. (2012). Re-defining “Telecentres". http://facilitating change.org/2012/08/telecentre -definition/

Mtega, W. P. and Melakani, A. W. (2009). "Analysing the Usage Pattern and Challenges of Telecentres among Rural Communities: Experience from Four Selected Telecentres in Tanzania". International Journal of Education and Development Using Information Technology (IJEDICT), 5(2), pp. 68-87ijedict.dec.uwi.edu/include/getdoc.php?id=4376\&article $=625 \ldots$ pdf

Munyua, H. (2000). Information and Communication Technologies for Rural Development and Food Security: Lessons from Field Experiences in Developing Countries. CAB International, Africa Regional Centre. http://www.fao.org/sd/CDdirect/CDre0055b.htm

Mukerji, M. (2010). "Access, Use, and Impact of Rural Telecentres: Findings from A Village-Level Exploration". Proceedings of the International conference on Information and Communication Technologies and Development, UK, 16.www.gg.rhul.ac.uk/ict4d/ictd2010/posters/ICT2010Mukerji.pdf

Murkerji, M. (2013). ICTs and Development: A Study of Telecentres in Rural India. Pulgrave MacMillan Link. springer.com/chapter/10.1057\%2F9781137005540_3

Nguo, J. (2015). ALIN, Welcome Note. www.alin.or.ke/i/welcome_Karibu

Osman, M.A. and Tanner, M. (2017). "The Influence of Telecentre Components on the Psychological empowerment of Underserved community Members in the Western Cape, South Africa". The Electronic Journal of Information Systems in Developing Countries (ejisdc), 81(4), pp. 1-29. www.is.cityu.edu.hk/staff/isrobert/ejisdc/81-4.pdf

Parkinson, S. (2005). Telecentres, access and development: Experience and Lessons from Uganda and South Africa. Ottawa: International Development Research Centre.

Pick, J.B. et al (2013). Technology for Development: Understanding Influences on Use of Rural Telecentres in India, Information Technology for Development, 20:4, 296 - 323. http://dx.doi.org

Prado, P. (2009). Bridging Digital Poverty: Adoption of Information and Communication Technologies at a Community Centre in the Dominican Republic. Unpublished Ph.D. dissertation, University of Miami, Florida, USA.

Proenza, F.J. (2001). "Telecentre Sustainability - Myths and Opportunities". Journal of Development Communication, vol. 12, No. 2), pp. 94-109. www.e-forall.org/pdf/telecentreSustanability.pdf

Sein, M.K. et al (2008). "Sustaining ICT for Development Projects: The Case of Grameenphone CIC". Telektronikk 104(2): 16-24.

Seretse, M., Chukwuere, J., Lubbe, S. and Klopper, R. (2018). "Problems around Accessing Information in Rural Communities". Alternation Journal, 25(1), pp. 214-244. https://journals.ukzn.ac.za/index.php/soa/article/view/1102 .

Communication Authority of Kenya http://www.ca.go.ke/index.php/telecommunication-

World Bank. (2009). World Development Report 2009: Reshaping Economic Geography. 
https://openknowledge.worldbank.org/handle/10986/5991

Zahurin, M. A.et al. (2010). A “ Model for Psychological Empowerment of Telecentre Users". Computer and Information Science, 3(3), 71-79. 